\title{
Comparative Study between Single-Level Anterior Cervical Discectomy and Fusion using Cage and Plate or Cage Alone
}

\author{
Youssef Barakat ${ }^{1}$, Alaa Rashad ${ }^{1}$, Mokhtar Ragab², Mohamed Ibrahim Abd Elrahman ${ }^{*}$ \\ Departments of ${ }^{1}$ Neurosurgery and ${ }^{2}$ Radiology, Faculty of Medicine, Al-Azhar University
}

*Corresponding Author: Mohamed Ibrahim Abd Elrahman, E-mail: drmohamedelhossieny@ gmail.com

\begin{abstract}
Background: anterior cervical discectomy and interbody fusion (ACDF) is a well-accepted management option for the treatment of persistent cervical radiculopathy or myelopathy due to cervical disc prolapse. Typically a fusion is performed to stabilize the segment, maintain foraminal height.

Objective: to prospectively analyze the effect of one-level ACDF, comparing stand-alone cages and cage-with-plate fixation constructs with respect to clinical outcomes and radiologic changes.

Patients and Methods: a total of 20 patients who underwent one-level for cervical disc disease and who completed 6 months of follow-up were included in this study. The patients were grouped into ACDF-Cage-only and ACDF-Cage-with-plate groups. The following parameters were assessed using radiographs: subsidence, adjacent disc space narrowing, clinical outcomes were assessed using the Odom's criteria.

Results: in the comparison of one-level ACDF-cage-only and ACDF-cage-with-plate groups, at the 3and 6-months follow-up: Regarding the functional outcome in the plate group $6(60 \%)$ patients had excellent outcome, $2(20 \%)$ patients had good outcome, $1(10 \%)$ had satisfactory and $1(10 \%)$ had poor outcome, while in the cage group $7(70 \%)$ patients had excellent outcome, 110\%) had good outcome, $1(10 \%)$ had satisfactory and $1(10 \%)$ had poor outcome.

Conclusion: our results showed that for single-level cases, plate fixation had no additional benefit versus cage-only, although the cage-with-plate fixation group had a lower incidence of cage sinking than did the cage-only group. We conclude that physicians should be aware of these possible advantages and disadvantages associated with using cervical plates in one-level ACDF.
\end{abstract}

Keywords: Diskectomy, Cervical Vertebrae, Spinal Fusion, Bone Plate.

\section{INTRODUCTION}

Anterior cervical discectomy and fusion (ACDF) have become a standard surgical procedure for treating degenerative disk disease associated with radiculopathy or myelopathy ${ }^{(1,2)}$.

Although stand-alone ACDF using cages can provide favorable outcomes, many surgeons have mentioned about the development of cage subsidence which may cause segmental kyphosis, acceleration of adjacent segment disease, and a decreased rate of fusion ${ }^{(3)}$.

Therefore some surgeons prefer to add an anterior plate to enhance stabilizing properties ${ }^{(4)}$.

\section{AIM OF THE STUDY}

It is to compare interbody fusion with stand-alone cage and interbody fusion with cage and plate for degenerative single-level cervical spine disorders.

Patients and Methods

\section{Study design:}

A comparative study of a clinical series of 20 patients with degenerative cervical disc treated by an anterior cervical discectomy procedure and fusion (ACDF) using either cage alone (ACDF-CA) or cages and plating construction (ACDF-CPC) in Al-Hussein university hospital and Al-Mataria teaching hospital during the period between December 2017 and June 2018. Patients were classified into 2 groups; group 1 $(\mathrm{N}=10)$ in whom interbody fusion was done using stand-alone cage, and group $2(\mathrm{~N}=10)$ in whom interbody fusion was done by cage augmented by anterior cervical plating.

\section{- Inclusion criteria:}

1- Degenerative disc disease single level within levels between $\mathrm{C} 3-\mathrm{C} 7$ causing:

- Neck pain and/or brachial neuralgia.

- Neurologic deficit.

2- Age between 18-70 years. 
3- Failure of conservative treatment for more than 6 weeks.

4- Or with progressive pain/ neurologic deficit.

\section{- Exclusion criteria:}

They were prior cervical spine surgery, gross instability secondary to trauma, History of disc or spine infection, spine tumor and pregnancy.

\section{- Patients and evaluation:}

Twenty patients were included in this study.

Patients were randomly divided into two equal groups. Group A consisted of 10 subjects who underwent ACDF-CA. Group B consisted of 10 subjects who underwent ACDFCPC.

- The preoperative protocol included:

1- Complete general and neurological examination.

2- Routine preoperative investigations.

3- Plain radiographs of the cervical spine antero-posterior (AP) and lateral views.

4- Magnetic resonance imaging MRI.

\section{Ethical approval:}

The study was approved by the Ethics Board of Al-Azhar University.

Confidentiality:

The data of the participant were recorded and analysed without any personal identifiers, by using coded information. The source documents and identification lists were archived in a secured facility per centre. Permission for accessing data will be documented per investigator.

\section{- Surgical procedure:}

Patients with single level cervical disk herniation and failed to achieve satisfactory recovery after conservative treatment were treated with either ACDF-CA or ACDF-CPC after careful evaluation of overall physical and mental status. The choice between ACDF-CA and ACDF-CPC was made by the patient after being provided detailed information about both surgical procedures by the surgeon.

Surgical procedures were carried out using the common anterolateral approach according to Smith-Robinson ${ }^{(5)}$ via a rightsided skin incision. The posterior osteophytes and any sub-ligamentous fragment were removed. Gentle decortication of the endplates was performed with a drill or curette. Interbody fusion is achieved using cervical cages alone or cages with anterior plating. The closure was done in the usual manner.

Oral pain medications were applied to ease postoperative pain for all the patients. Soft cervical collar was used to protect the patients up to a month after the surgery. Patients were encouraged to attend low intensity daily activities after the removal of the collar, and were told to engage in normal activities including sports 3 months after the surgery.

- Postoperative outcome assessment included:

\section{a- Clinical outcome:}

Especially noting sensory and motor status compared with the pre-operative assessment.

\section{b- Functional outcome:}

It was assessed according to Odom's ${ }^{(6)}$ criteria.

It was defined as:

1- Excellent in patients who had no complaints referable to cervical disc disease and were able to carry on their daily routines without any impairment.

2- Good outcome was defined as intermittent discomfort related to cervical disc disease which, however, did not significantly interfere with work.

3- Satisfactory outcome was defined as subjective improvement but limited physical activities.

4- Poor outcome included patients who did not improve or worsened after surgery.

c- Radiological outcome: plain X-rays of the cervical spine.

\section{Radiographs were reviewed to evaluate:}

- Cage position.

- The shape of the cervical spine in the neutral position, which was described as lordotic, straight, or kyphotic.

- The height of the intervertebral disc.

- Fusion which was defined by the presence of trabecular bone, and bony bridging formation between superior and inferior endplates

\section{Statistical analysis}

Independent sample t-tests were used to compare the parameters between two groups 
at each time point. Continuous variables are shown either as mean \pm standard error from means or as median (min; max). Percentages were calculated for categorical variables. Differences between the two compared groups in the categorical variables were assessed using a Chi-square test. Differences between continuous variables were tested using a Student's T-test. The difference was considered significant when $P<0.05$.

\section{Limitation of the study}

The present study has several limitations. The follow-up period was short. However, considering the fact that subsidence and fusion did occur within 12 months, it was sufficient for evaluating retention and motion stabilization. However, a longer follow-up period would be needed to investigate adjacent segment degeneration and long-term stabilization.

\section{RESULTS}

Our study was a comparative study that was conducted on 20 patients with cervical disc prolapse who were surgically treated by ACDF in Al-Hussein University hospital and AlMataria Teaching hospital during the period between December 2017 and November 2018. Patients were classified into 2 groups; group 1 $(\mathrm{N}=10)$ in whom interbody fusion was done using a stand-alone cage, and group $2(\mathrm{~N}=10)$ in whom interbody fusion was done by cage augmented by anterior cervical plating.
In the plate group, the age ranged from 40 to 65 years with a mean of 54.20 years and SD 8.27, while in the cage group the age ranged from 32 to 54 years with a mean of 41.80 years and SD 7.63.

The sex distribution among this study was 17 males (85\%) and 3 females (15\%). Regarding the two studied groups, the plate group showed $80 \%$ males and $20 \%$ females, while the cage alone group showed $90 \%$ males and $10 \%$ females.

Regarding the clinical picture, the most common symptoms where Neck pain + radiculopathy with $70 \%$, after which came Radiculomyelopathy with 20\% and Myelopathy with $10 \%$.

In this study, the distribution of the clinical picture among the two studied groups, there were 8 patients $(80 \%)$ of the plate group complaining of Neck pain + radiculopathy, while in the cage alone group 6 patients (60\%) complained of Neck pain+ radiculopathy.

Regarding the radiculomyelopathic patients, there were 3 patients (30\%) in the plate group and 1 patient $(10 \%)$ in the cage group. While the myelopathic there was 1 patient in the plate group (10\%) and there was 1 patient the cage group $(10 \%)$.

The most common operated levels (Table 1): in the plate group were C5-6 (60\%) followed by $\mathrm{C} 4-5$ (30\%), while in the cage group the most common levels were C56(70\%), followed by C6-7 level (20\%).

Table (1): Comparison between the two groups regarding the affected level:

\begin{tabular}{|l|c|c|c|c|c|c|c|}
\hline \multirow{2}{*}{ Diagnosis } & \multicolumn{2}{|c|}{$\begin{array}{c}\text { Cage alone } \\
\text { group }\end{array}$} & \multicolumn{2}{c|}{$\begin{array}{c}\text { Cage and } \\
\text { plate group }\end{array}$} & \multirow{2}{*}{$\begin{array}{c}\text { Test } \\
\text { value }\end{array}$} & \multirow{2}{*}{ P-value } & Sig. \\
\cline { 2 - 5 } & No. & $\%$ & No. & $\%$ & & & \\
\hline C3c4 & 1 & $10.0 \%$ & 1 & $10.0 \%$ & & NS \\
C4c5 & 0 & $0.0 \%$ & 3 & $30.0 \%$ & 5.077 & 0.166 & \\
C5c6 & 7 & $70.0 \%$ & 6 & $60.0 \%$ & & & \\
C6c7 & 2 & $20.0 \%$ & 0 & $0.0 \%$ & & & \\
\hline
\end{tabular}

P-value >0.05: Non significant (NS); P-value <0.05: Significant (S); P-value< 0.01: highly significant (HS) $\quad *$ :Chi-square test

In this study, we followed our patients immediate postoperative, two weeks, three months and six months post-operative, where we evaluated subjective clinical signs and radiological finding by $\mathrm{x}$ ray.

Regarding the functional outcome (Table 2): in the plate group 6 patients had an excellent outcome, 2 patients had a good outcome, 1 had satisfactory and 1 had a poor outcome, while in the cage group 7 patients had an excellent outcome, 1 had a good outcome, 1 had satisfactory and 1 had a poor outcome.

Table (2): Comparison between the two groups regarding outcome according to Odam's criteria: 


\begin{tabular}{|l|c|c|c|c|c|c|c|}
\hline \multirow{2}{*}{ Out come } & \multicolumn{2}{|c|}{$\begin{array}{c}\text { Cage alone } \\
\text { group }\end{array}$} & \multicolumn{2}{c|}{$\begin{array}{c}\text { Cage and plate } \\
\text { group }\end{array}$} & \multirow{2}{*}{$\begin{array}{c}\text { Test } \\
\text { value* }\end{array}$} & \multirow{2}{*}{ P-value } & \multirow{2}{*}{ Sig. } \\
\cline { 2 - 5 } & No. & $\%$ & No. & \% & & \\
\hline Poor & 1 & $10.0 \%$ & 1 & $10.0 \%$ & & & \\
Satisfactory & 1 & $10.0 \%$ & 1 & $10.0 \%$ & 0.410 & 0.938 & NS \\
Good & 1 & $10.0 \%$ & 2 & $20.0 \%$ & & & \\
Excellent & 7 & $70.0 \%$ & 6 & $60.0 \%$ & & \\
\hline
\end{tabular}

P-value >0.05: Non significant (NS)

*:Chi-square test

Regarding complications (Table 3), there were no patients with post-operative Vocal cord dysfunction. But there were 2 patients suffered from Dysphagia (transient) one in each group. There was no post-operative infection. No patients suffered from Neurological deterioration and there was no Keloid formation. In our study, there were no complications related to the cages as extrusion, but there was 1 case of cage sinking at the vertebral bodies. We didn't have to remove implants from any patient. We did not use the known measure to assess cage subsidence as there was no constant scale for all the images.

Table (3): Comparison between the two groups regarding complications and improvement:

\begin{tabular}{|c|c|c|c|c|c|c|c|c|}
\hline & \multicolumn{2}{|c|}{$\begin{array}{l}\text { Cage alone } \\
\text { group }\end{array}$} & \multicolumn{2}{|c|}{$\begin{array}{c}\text { Cage and plate } \\
\text { group }\end{array}$} & \multirow{2}{*}{$\begin{array}{c}\text { Test } \\
\text { value }\end{array}$} & \multirow[t]{2}{*}{ P-value } & \multirow[t]{2}{*}{ Sig. } \\
\hline & & No. & $\%$ & No. & $\%$ & & & \\
\hline \multirow{2}{*}{ Complications } & Negative & 9 & $90.0 \%$ & 9 & $90.0 \%$ & \multirow{2}{*}{0.001} & \multirow{2}{*}{1.000} & \multirow{2}{*}{ NS } \\
\hline & Dysphasia & 1 & $10.0 \%$ & 1 & $10.0 \%$ & & & \\
\hline \multirow{2}{*}{$\begin{array}{l}\text { Instrument } \\
\text { complications }\end{array}$} & Negative & 9 & $90.0 \%$ & 10 & $100.0 \%$ & \multirow[b]{2}{*}{1.053} & \multirow[b]{2}{*}{0.305} & \multirow[b]{2}{*}{ NS } \\
\hline & \begin{tabular}{|l} 
Cage \\
sinking
\end{tabular} & 1 & $10.0 \%$ & 0 & $0.0 \%$ & & & \\
\hline \multirow{3}{*}{ Improvement } & $\begin{array}{l}\text { Not } \\
\text { improved }\end{array}$ & 0 & $0.0 \%$ & 1 & $10.0 \%$ & \multirow{3}{*}{2.000} & \multirow{3}{*}{0.368} & \multirow{3}{*}{ NS } \\
\hline & Rebound & 1 & $10.0 \%$ & 0 & $0.0 \%$ & & & \\
\hline & Improved & 9 & $90.0 \%$ & 9 & $90.0 \%$ & & & \\
\hline \multirow{2}{*}{ Adjacent Level } & Negative & 9 & $90.0 \%$ & 10 & $100.0 \%$ & \multirow{2}{*}{1.053} & \multirow{2}{*}{0.305} & \multirow{2}{*}{ NS } \\
\hline & Positive & 1 & $10.0 \%$ & 0 & $0.0 \%$ & & & \\
\hline
\end{tabular}

P-value >0.05: Non significant (NS)

*:Chi-square test

\section{DISCUSSION}

Anterior cervical discectomy and fusion (ACDF) is the gold standard treatment for cervical disc herniation ${ }^{(7)}$.

Many technical modifications have been reported since its original description by Smith and Robinson ${ }^{(5)}$.

ACDF using an intervertebral cage is credited with promoting instant stability, restoration of the neural foraminal height and interbody fusion ${ }^{(8)}$.

polyetheretherketone (PEEK) cages are currently the most preferred. Compared with titanium and carbon fiber cages, PEEK cages are more biocompatible and radiolucent, which allows good radiological evaluation ${ }^{(9)}$.

The addition of an anterior plate system reduces the problem of cage extrusion and collapse but is itself associated with problems such as screw or plate dislodgement, dysphagia, and soft-tissue injury ${ }^{(\mathbf{1 0})}$.

To decrease the risk of such complications, several types of interbody fusion cage have been developed recently and are used widely in clinical practice ${ }^{\mathbf{1 1 1}}$.

The most common operated levels in the plate group were (C5-6). This prevalence can be explained by the concentration of forces at that level during neck flexion, or the decrease of canal diameter in relation to the cord diameter which makes this level more sensitive to disc prolapse ${ }^{(\mathbf{1 2})}$.

The aim of our study was to determine the short-term outcome results of cervical decompression techniques with or without an instrumented plate. We also aimed to evaluate the impact of these surgical procedures in terms 
of pain relief and improvement in individual function.

Most of the patients achieved good overall pain and disability improvement within the first 3-month follow-up. This shows that carefully selected patients can achieve the desired levels of pain relief and functional improvement.

Comparing our study with previous studies

Bose described $97.9 \%$ fusion with plates with acceptable instrumentation-related morbidity, which improves with experience $(10.7 \%$ instrument-related morbidity in the first 38 cases and $1.69 \%$ in last 59 cases) ${ }^{(\mathbf{1 3})}$.

Cauthen reported 348 patients operated by ACDF and found $13 \%$ required an additional operation: $7 \%$ required revision fusion surgery with the addition of plate fixation ${ }^{(\mathbf{1 4})}$.

Among 54 patients who underwent anterior cervical discectomy and reconstruction, cage-plate constructs resulted in shorter fusion duration and lower subsidence rates; although all other clinical and radiological parameters including global and segmental alignment were similar in both groups ${ }^{(\mathbf{1 5})}$.

Observed better prevention of segmental kyphosis and subsidence with cageplate constructs. Bartels et al. reported subsidence in $29.2 \%$ and non-union in $4.3 \%$ following stand-alone cages ${ }^{(\mathbf{1 6})}$.

\section{CONCLUSION}

In conclusion, two surgical procedures for cervical disc herniation were compared, the use of cages alone versus cages and anterior plating. Both procedures were comparable in achieving pain relief and functional improvement. Although the plate method was superior to the cage alone method in terms of preserving alignment and disc height achievement, Short-term outcome was almost the same.

\section{REFERENCES}

1. Goffin J, Van Calenbergh F, van Loon J et al. (2003): Intermediate follow-up after treatment of degenerative disc disease with the Bryan Cervical Disc Prosthesis: singlelevel and bi-level. Spine, 28(24): 26732678.

2. Assietti R, Beretta F and Arienta C (2012): Two-level anterior cervical discectomy and cage-assisted fusion without plates. Neurosurgical Focus, 12(1):1-5.
3. Niu C, Liao J, Chen W and Chen L (2010): Outcomes of interbody fusion cages used in 1 and 2-levels anterior cervical discectomy and fusion: titanium cages versus polyetheretherketone (PEEK) cages. Clinical Spine Surgery, 23(5):310316.

4. Ji GY, Oh CH, Shin DA et al. (2015): Stand-alone cervical cages versus anterior cervical plates in 2-level cervical anterior interbody fusion patients: analysis of adjacent segment degeneration. Clinical Spine Surgery, 28(7):E433-E438

5. Smith GW and Robinson RA (1958): The treatment of certain cervical-spine disorders by anterior removal of the intervertebral disc and interbody fusion. $\mathrm{J}$ Bone Joint Surg Am., 40-A: 607-624.

6. Odom GL, Finney $W$ and Woodhall $B$ (1958): Cervical disk lesions. Journal of the American Medical Association, 166(1): 23-28.

7. Samartzis D, Shen FH, Goldberg EJ et al. (2005): Is autograft the gold standard in achieving radiographic fusion in one-level anterior cervical discectomy and fusion with rigid anterior plate fixation?. Spine, 30(15):1756-1761.

8. Yang JJ, Yu CH, Chang BS et al. (2011): Subsidence and nonunion after anterior cervical interbody fusion using a standalone polyetheretherketone (PEEK) cage. Clinics in Orthopedic Surgery, 3(1): 16-23.

9. Cho DY, Liau WR, Lee WY et al. (2002): Preliminary experience using a polyetheretherketone (PEEK) cage in the treatment of cervical disc disease. Neurosurgery, 51(6): 1343-1350.

10. Fujibayashi $S$, Neo $M$ and Nakamura $T$ (2008): Stand-alone interbody cage versus anterior cervical plate for treatment of cervical disc herniation: sequential changes in cage subsidence. Journal of Clinical Neuroscience, 15(9): 1017-1022.

11. Fujibayashi $S$, Neo $M$ and Nakamura $T$ (2008): Stand-alone interbody cage versus anterior cervical plate for treatment of cervical disc herniation: sequential changes in cage subsidence. Journal of Clinical Neuroscience, 15(9): 1017-1022. 
12. Vavruch $L$, Hedlund $R$ and Javid $D$ (2002): A prospective randomized comparison between the cloward procedure and a car- bon fiber cage in the cervical spine: a clinical and radiologic study. Spine, 27: 1694-1701.

13. Bose B (1998): Anterior cervical fusion using Caspar plating: analysis of results and review of the literature. Surgical Neurology, 49(1): 25-31.

14. Cauthen JC, Kinard RE, Vogler JB et al. (1998): Outcome analysis of noninstrumented anterior cervical discectomy and interbody fusion in 348 patients. Spine, 23(2):188-192.
15. Lee CH, Hyun SJ, Kim MJ et al. (2013): Comparative analysis of 3 different construct systems for single-level anterior cervical discectomy and fusion: standalone cage, iliac graft plus plate augmentation, and cage plus plating. Clinical Spine Surgery, 26(2): 112-118.

16. Bartels RH, Donk R and van Dijk Azn R (2001): Height of cervical foramina after anterior discectomy and implantation of a carbon fiber cage. Journal of Neurosurgery: Spine, 95(1): 40-42. 